Original Articles

\title{
A clinical audit on maintenance of optimal peripheral oxygen saturation in preterm neonates needing mechanical ventilation at a level III neonatal intensive care unit
}

\author{
*A M B W M R N N Ekneligoda ${ }^{1}$, N C Gamhewage ${ }^{2}$, M Weerasekera $^{3}$
}

Sri Lanka Journal of Child Health, 2020; 49(1):03-07

\begin{abstract}
Introduction: With increasing survival of preterm neonates, oxygen therapy has become an integral part of neonatal respiratory support. In Sri Lanka survival rate of extremely preterm babies is nearly $70 \%$. Most recent studies show oxygen saturations $\left(\mathrm{SpO}_{2}\right)$ of $91-95 \%$ in preterm neonates maximize survival while minimizing side effects such as retinopathy of prematurity. Oxygenation can be optimized by controlling ventilator settings- i.e. fraction of inspired oxygen $\left(\mathrm{FiO}_{2}\right)$, inspiratory time and mean airway pressure.
\end{abstract}

Objective: To study the $\mathrm{SpO}_{2}$ trend maintained in ventilated (both invasive and non-invasive) preterm babies at the neonatal intensive care unit of Sri Jayewardenepura General Hospital.

Method: Study was done in March 2018 on ventilated preterm babies $<34$ weeks gestation and birth weight $<1.5 \mathrm{~kg}$. Neonates with pulmonary hypertension, bronchopulmonary dysplasia, cyanotic heart disease, major congenital anomalies and neonates on palliative care were excluded. $\mathrm{SpO}_{2}$ trend and related ventilator settings i.e. $\mathrm{FiO}_{2}$, peak inspiratory pressure / pressure support, and positive end expiratory pressure, were recorded daily at $8 \mathrm{am}$ and $2 \mathrm{pm} . \mathrm{SpO}_{2}$ trend was observed for 10 minutes and the most persisting value taken to minimize observation bias. Data were analysed using SPSS 20.

${ }^{1}$ Registrar in Paediatrics, Sri Jayawardenepura
General Hospital, Sri Lanka, ${ }^{2}$ Lecturer in
Paediatrics, University of Sri Jayewardenepura,
Sri Lanka, ${ }^{3}$ Consultant Neonatologist, Sri
Jayawardenepura General Hospital, Sri Lanka
*Correspondence: nnekneligoda@yahoo.com

(iD) https://orcid.org/0000-0003-2323-6115

(Received on 24 March 2019: Accepted after revision on 24 May 2019)

The authors declare that there are no conflicts of interest

Personal funding was used for the project.

Open Access Article published under the

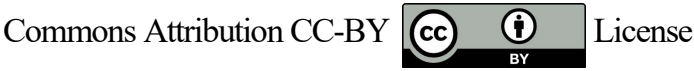

Results: Ten preterm neonates with 211 observations were studied. Maturity ranged from 27-33 weeks. Mean birth weight was $1.24 \mathrm{~kg}$ $(\mathrm{SD}=0.43)$ and $5(50 \%)$ babies were extremely low birth weight. In 158 (74.9\%) observations, $\mathrm{SpO}_{2}$ was $>95 \%$. Optimal $\mathrm{SpO}_{2}$ was noted only in $52 / 211$ $(24.6 \%)$ observations. In observations with $\mathrm{SpO}_{2}$ $>95 \%$ where invasive ventilation was used, 35/120 (29.1\%) had minimum ventilator settings i.e. PiP$14 \mathrm{H}_{2} \mathrm{Ocm}$ and $\mathrm{FiO}_{2}-21 \%$. Among babies with noninvasive modes, $68.4 \%$ of observations had a $\mathrm{FiO}_{2}$ of $21 \%$ with a PEEP of 5 . Therefore, in $59.5 \%$ there was no room to reduce $\mathrm{FiO}_{2}$ further and in $29.1 \%$ of the instances with invasive ventilation there was no room for reducing ventilator settings. $\mathrm{SpO}_{2}$ was $<89 \%$ only on 1 occasion.

Conclusions: Even though in most of the instances minimum ventilator settings were used still there was room for further reduction.

DOI: http://dx.doi.org/10.4038/sljch.v49i1.8918

(Key words: Preterm, optimal oxygen saturation, hyperoxia, retinopathy of prematurity)

\section{Introduction}

According to the World Health Organisation most of the preterm births take place in South and Southeast Asia which increases the health burden in the region ${ }^{1}$. A retrospective study conducted in our unit, evaluating the pre-discharge mortality of extreme preterm babies revealed an overall survival rate of $68 \%$, with $85 \%$ survival in babies born at 28 weeks of gestation ${ }^{2}$. Oxygen therapy is frequently used in neonatal units as an integral part of respiratory support with a wide range of invasive and non-invasive ventilatory modalities ${ }^{3}$. Even though intense respiratory support has improved the survival of preterm neonates, excess oxygen therapy is associated with higher incidences of chronic lung disease, retinopathy of prematurity (ROP), especially in extremely premature infants and in infants with a very low birth weight, while inadequate oxygenation will cause significant neurocognitive sequelae e $^{3-5}$.Therefore it is important to control the settings to assure optimal oxygenation to gain the benefits while minimizing the adverse effects for a favourable outcome. 
Most recent studies (SUPPORT, BOOST II) have shown oxygen saturations of $91-95 \%$ in preterm neonates maximize survival while minimizing potential side effects ${ }^{4,5}$. Since oxygenation depended on the fraction of inspired oxygen $\left(\mathrm{FiO}_{2}\right)$, inspiratory time and mean airway pressures (MAP), which in turn depends on the peak inspiratory pressure (PiP) and the positive end expiratory pressure (PEEP), by controlling the above variables optimal oxygen saturations can be ensured ${ }^{4}$.

In a systematic review done by Van Zanten HA, et $a l$, it was found that in 12 studies selected, compliance in maintaining target oxygen saturation in preterm neonates receiving oxygen therapy is low, especially in maintaining the $\mathrm{SpO}_{2}$ below the upper limit $^{6}$. In a multicentre study, Hagadom et al observed that $\mathrm{SpO}_{2}$ was below or above the target range in $0-47 \%$ and $5-90 \%$ respectively of the monitored time ${ }^{7}$. A study done by Van der Eijk et al reported similar results ${ }^{8}$. A study including infants receiving supplemental oxygen with CPAP revealed in $9 \% \mathrm{SpO}_{2}$ was below and in $90 \% \mathrm{SpO}_{2}$ was above the target range ${ }^{6}$. Further, several root causes were identified for hyperoxia in preterm neonates in previous studies including inappropriately set alarms, lack of awareness of consequences of hyperoxia and increased workload $^{3,6}$. Thus, this study was done as the first step in minimizing incidences of hyperoxia among ventilated preterm neonates in the unit.

\section{Objectives}

To study the trend of peripheral oxygen saturation $\left(\mathrm{SpO}_{2}\right)$ maintained in ventilated (both invasive and non-invasive) preterm neonates at the neonatal intensive care unit (NICU) of Sri Jayewardenepura General Hospital (SJGH).

\section{Method}

A study was carried out in the last 2 weeks of March, 2018 involving preterm neonates born before 34 weeks of gestation, with a birth weight of less than $1.5 \mathrm{~kg}$ needing ventilatory support, both invasive and non-invasive at the NICU of SJGH. Neonates who were diagnosed to have established bronchopulmonary dysplasia, pulmonary hypertension, cyanotic heart disease, major congenital anomalies and neonates receiving only palliative care, were excluded from the study. Trend of oxygen saturation $\left(\mathrm{SpO}_{2}\right)$ by pulse oximetry and related ventilator settings were prospectively studied twice daily at 8 am and $2 \mathrm{pm}$. Before noting down the pulse oximetry value, $\mathrm{SpO}_{2}$ trend was observed for 10 minutes and the most persisting value was taken as the $\mathrm{SpO}_{2}$ at the time of observation, to minimize observational bias. With regard to ventilator settings, determinants of oxygenation, i.e. $\mathrm{FiO}_{2}, \mathrm{MAP}$ (PiP/Ps and PEEP) were recorded. Data was analysed using SPSS 20. Observations with $\mathrm{SpO}_{2}>95 \%$ were taken as hyperoxic events while observations with $\mathrm{SpO}_{2}$ $<91 \%$ were taken as hypoxic.

\section{Results}

Ten preterm neonates were included in the study of which $3(30 \%)$ were extremely preterm. The maturity ranged from 27 weeks of gestation to 33 weeks. Their mean birth weight was $1.24 \mathrm{~kg}$ $(\mathrm{SD}=0.43)$ and $5(50 \%)$ were extremely low birth weight. A total of 211 observations was made during the study period. Both invasive [controlled mandatory ventilation (CMV), synchronised intermittent mandatory ventilation (SIMV)] and non-invasive modes [non-invasive intermittent positive pressure ventilation (NIPPV), nasal continuous positive pressure ventilation (NCPAP)] were used in providing respiratory support in the study population. Most of the times (74.4\%, 157/211) an invasive mode of respiratory support was given and in $73 \%$ of the observations SIMV mode was used while CMV was used least (1.4\%). This is shown in Table 1.

Table 1: Frequencies of modes of ventilation used

\begin{tabular}{|l|c|}
\hline \multicolumn{1}{|c|}{ Mode of ventilation } & Frequency (\%) \\
\hline Synchronised intermittent mandatory ventilation (SIMV) & $154(73.0)$ \\
\hline Controlled mandatory ventilation (CMV) & $03(01.4)$ \\
\hline Non-invasive intermittent positive pressure ventilation (NIPPV) & $47(22.3)$ \\
\hline Nasal continuous positive pressure ventilation (NCPAP) & $07(03.3)$ \\
\hline
\end{tabular}

Most of the time $(74.9 \%, 158 / 211) \mathrm{SpO}_{2}$ was maintained above $95 \%$ and only in $24.6 \%(52 / 211)$ of the observations, the $\mathrm{SpO}_{2}$ was in the accepted range (91\%-95\%). Out of these, in $22(13.9 \%)$ of the observations $\mathrm{SpO}_{2}$ was maintained at $100 \%$. Only one observation had a $\mathrm{SpO}_{2}$ of $<89 \%$. In the majority $(74.1 \%)$ of the observations with $\mathrm{SpO}_{2}$ $>95 \%$, the mode of ventilation was SIMV. Use of different modes of ventilation in observations with a $\mathrm{SpO}_{2}>95 \%$ is shown in Figure 1 


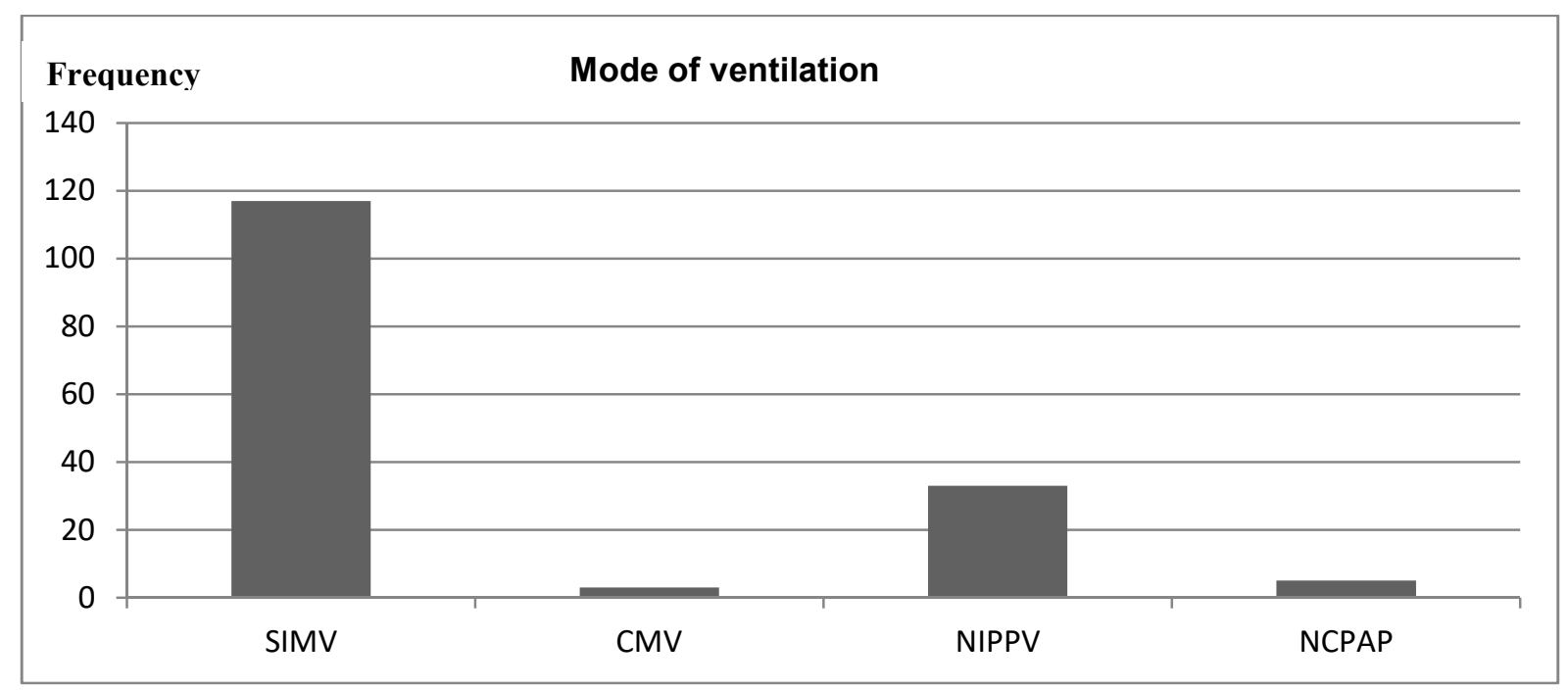

Figure 1: Use of different modes of ventilation in observations with a $\mathrm{SpO}_{2}>95 \%$

Frequencies of $\mathrm{FiO}_{2}$ used according to different ventilatory modes in observations with a $\mathrm{SpO}_{2}$ $>95 \%$ are shown in Table 2. $\mathrm{FiO}_{2}$ of these observations ranged from $21 \%$ to $60 \%$.
Interestingly, in $94 / 158 \quad(59.5 \%)$ of above observations $\mathrm{FiO}_{2}$ was $21 \%$ and only in 7 incidences $\mathrm{FiO}_{2}$ was $40 \%$ or above.

Table 2

Frequencies of $\mathrm{FiO}_{2}$ used according to different ventilatory modes in observations with a $\mathrm{SpO}_{2}>95 \%$

\begin{tabular}{|l|c|c|c|c|}
\hline \multicolumn{1}{|c|}{ Mode/FiO $_{2}$} & $\mathbf{2 1 - 3 0 \%}$ & $\mathbf{3 1 - 4 0 \%}$ & $\mathbf{4 1 - 5 0 \%}$ & $\mathbf{5 1 - 6 0 \%}$ \\
\hline Non-invasive intermittent positive pressure ventilation & 29 & 02 & 01 & 01 \\
\hline Synchronised intermittent mandatory ventilation & 112 & 05 & - & - \\
\hline Controlled mandatory ventilation & 02 & 01 & - & - \\
\hline Nasal continuous positive pressure ventilation & 05 & - & - & - \\
\hline
\end{tabular}

In the above category peak inspiratory pressures used ranged from $6 \mathrm{H}_{2} \mathrm{Ocm}$ to $22 \mathrm{H}_{2} \mathrm{Ocm}$ with a mean $\mathrm{PiP}$ of $15.5 \mathrm{H}_{2} \mathrm{Ocm}(\mathrm{SD}=3.3)$. A PiP of $22 \mathrm{H}_{2} \mathrm{Ocm}$ was only used in NIPPV mode.

Analysis of the ventilator settings used in incidences with a $\mathrm{SpO}_{2}$ of $>95 \%$ revealed that in observations with an invasive mode of ventilation, $29.1 \%(35 / 120)$ had minimum settings defined as a PiP of $14 \mathrm{H}_{2} \mathrm{O} \mathrm{cm}, \mathrm{FiO}_{2}$ of $21 \%{ }^{4}$. Among babies with non-invasive modes, $68.4 \% \quad(26 / 38)$ of observations had a $\mathrm{FiO}_{2}$ of $21 \%$. Therefore in $59.5 \%(94 / 158)$ of the instances there was no room to reduce $\mathrm{FiO}_{2}$ further and in $29.1 \%$ of the instances with an invasive mode of ventilation there was no room for further reducing both the $\mathrm{FiO}_{2}$ and the PiP to obtain a lower $\mathrm{SpO}_{2}$.

When considering the gestational age of the observed preterm neonates, in extremely preterm neonates $\mathrm{SpO}_{2}$ was maintained above $95 \%$ in $67.2 \%$ of the observations, whereas in neonates with a gestational age of 28-34 weeks, $\mathrm{SpO}_{2}$ was $>95 \%$ in $83.7 \%$ of the observations. There was no statistical significance in the mean $\mathrm{SpO}_{2}$ maintained in extremely preterm babies and babies with a gestation of 28-34 weeks (96.4\% Vs 97.0\%). The mean $\mathrm{FiO}_{2}$ used in extremely preterm neonates was $25.3 \%$ and in the other group $22.9 \%$, which was statistically significant $(p=0.0007)$. There was no statistical difference in the pressures used in the two groups $(p=0.46)$.

With regard to the birth weight, in $71.1 \%$ of the instances $\mathrm{SpO}_{2}$ was $>95 \%$ in extremely low birth weight preterm neonates whereas in preterm neonates with a birth weight of $>1000 \mathrm{~g}$, in $82.6 \%$ of the instances $\mathrm{SpO}_{2}$ was $>95 \%$. There was no significant difference between the $\mathrm{FiO}_{2}$ used in the 2 groups $(p=0.078)$.

\section{Discussion:}

It is clear, in practice more focus was on preventing hypoxia rather than hyperoxia which was also revealed in other studies. The study on "Maintaining optimal oxygen saturations in preterm neonates" revealed that in setting $\mathrm{SpO}_{2}$ alarms, though the hypoxia alert was set appropriately, the upper alarm limit was commonly set at $\geq 98 \%{ }^{3}$. Also, a systematic review done by Van Zanten HA, et al revealed low compliance on oxygen targets and inappropriate alarm settings ${ }^{6}$.

In our study, observations were made only twice a day whereas in the study done by Lau YY, et al observations were made throughout the day every 
15 minutes apart and the percentage of time with a higher $\mathrm{SpO}_{2}$ value was documented ${ }^{3}$. Though this method will give more accurate results it needs more technical facilities such as multi-para monitors for each neonate allowing continuous $\mathrm{SpO}_{2}$ monitoring and to retrieve recorded values. Also this requires more human effort which was a practical obstacle in our setting. However, the results of our study (i.e. in $74.9 \%$ of the instances $\mathrm{SpO}_{2}$ was $>95 \%$ ) were consistent with the previous studies which showed that incidences of hyperoxia ranged from $30 \%-90 \%$ prior to interventions $\mathrm{s}^{3,6}$.

Interestingly, in the study, most of the observations with $\mathrm{SpO}_{2}>95 \%$ had low ventilator-settings. $\mathrm{FiO}_{2}$ was $21 \%$ in nearly $60 \%$ of the observations with higher $\mathrm{SpO}_{2}$. Even though most of the observations with a higher $\mathrm{SpO}_{2}$ had comparatively low settings at times there was space to come down on ventilator settings. However due to limitations in observations made, and influence of other factors which were not explored more expanded studies are needed for a clear understanding.

It is interesting to note that the incidences of hyperoxia among extremely preterm neonates and extremely low birth weight neonates who are at an increased risk of damage with a higher oxygen saturation were similar to the rest of the observations. However it would be beneficial if $\mathrm{FiO}_{2}$ used in extremely preterm neonates is tightly regulated to minimize hyperoxia.

Apart from the limitations in the observations made there can be other factors that might contribute to higher saturations observed. Lau YY, et al and many other studies have identified several root causes for not maintaining optimal $\mathrm{SpO}_{2}$ including lack of proper guidelines on titrating $\mathrm{FiO}_{2}$, improper alarm setting, heavy workload of the health care staff forgetting to wean infants to a lower $\mathrm{FiO}_{2}$, lack of awareness on adverse out comes with higher $\mathrm{SpO}_{2}$, etc ${ }^{3,6}$. Expanding the study with more frequent observations and to find out contributing causes in the setting will be beneficial.

There are other factors which determine ventilator settings in addition to $\mathrm{SpO}_{2}$. A more expanded study with continuous observations to demonstrate the fluctuations of $\mathrm{SpO}_{2}$ will be beneficial for a more clear understanding. Linking long term outcomes such as development of retinopathy of prematurity (ROP), chronic lung disease in preterm babies exposed to higher oxygen saturations would be another interesting area to look in to in future studies. Identifying the possible underlying causes for not maintaining optimal $\mathrm{SpO}_{2}$ (e.g. incorrectly set alarms, lack of knowledge among the medical staff on optimal $\mathrm{SpO}_{2}$ levels, etc.) would be beneficial in improving the quality of care.

To minimize maintenance of higher $\mathrm{SpO}_{2}$ levels in preterm neonates in the unit, algorithms for titrating $\mathrm{FiO}_{2}$, aiming at maintaining optimal $\mathrm{SpO}_{2}$ levels as done in previous studies and using visual reminders to minimize episodes of hyperoxia and for correct alarm setting are suggested. Finally in keeping up with plan-do-study-act cycle conducting the same study after implementations to assess the improvement is needed.

\section{Conclusions}

$\mathrm{SpO}_{2}$ of preterm infants were maintained at higher levels at most instances in our unit. Though low ventilator settings were used at most instances, still there was room for improvement.

\section{References}

1. World Health Organisation, Born Too Soon; The global action report on preterm birth. Available from: https://www.who.int/pmnch/media/news/2 012/201204_borntoosoon-report.pdf2012

2. Gamhewage NC, Weerasekara M, Wijayaratne J. Pre-discharge neonatal morbidity and mortality in extremely preterm babies managed at Sri Jayewardenepura Teaching Hospital. Sri Lanka Journal of Child Health 2018; 47(2):155-8.

https://doi.org/10.4038/sljch.v47i2.8483

3. Lau YY, Tay YY, Shah VA, Chang P, Loh KT. Maintaining optimal oxygen saturation in preterm infants. The Permanente Journal 2011; 15(1):e108-13.

4. Amitava Sengupta, An introduction to mechanical ventilation in the newborn. The Text Book of Neonatal Ventilation, 37th Annual Convention of National Neonatology Forum, India.

5. Glass HC, Costarino AT, Stayer SA, Brett CM, Cladis F, Davis PJ. Outcomes for extremely premature infants. Anesthesia and Analgesia, 2015; 120(6):1337-5. https://doi.org/10.1213/ANE.0000000000 000705

PMid: 25988638 PMCid: PMC4438860

6. Van Zanten HA, Tan RN, van den Hoogen A, Lopriore E, Te Pas AB. Compliance in oxygen saturation targeting in preterm infants: a systematic review. European 
Journal of Paediatrics 2015; 174(12):

1561-72

https://doi.org/10.1007/s00431-015-2643-

0

PMid: 26468116 PMCid: PMC4662723

7. Hagadorn JI, Furey AM, Nghiem TH, Schmid CH, Phelps DL, Pillers DA, Cole $\mathrm{CH}$. Achieved versus intended pulse oximeter saturation in infants born less than 28 weeks' gestation: the AVIOx study. Pediatrics 2006; 118:1574-82.

https://doi.org/10.1542/peds.2005-0413

PMid: 17015549
8. Van der Eijk AC, Dankelman J, Schutte S, Simonsz HJ, Smit BJ. An observational study to quantify manual adjustments of the inspired oxygen fraction in extremely low birth weight infants. Acta Paediatr (Oslo, Norway: 1992) 2012; 101:e97e104.

https://doi.org/10.1111/j.16512227.2011.0 2506.x

PMid: 22040264 